\title{
Linking power and flow in rotor-stator mixers
}

DOI:

10.1016/j.ces.2019.06.039

\section{Document Version}

Accepted author manuscript

Link to publication record in Manchester Research Explorer

\section{Citation for published version (APA):}

John, T. P., Panesar, J. S., Kowalski, A., Rodgers, T. L., \& P. Fonte, C. (2019). Linking power and flow in rotorstator mixers. Chemical Engineering Science, 207, 504-515. https://doi.org/10.1016/j.ces.2019.06.039

\section{Published in:}

Chemical Engineering Science

\section{Citing this paper}

Please note that where the full-text provided on Manchester Research Explorer is the Author Accepted Manuscript or Proof version this may differ from the final Published version. If citing, it is advised that you check and use the publisher's definitive version.

\section{General rights}

Copyright and moral rights for the publications made accessible in the Research Explorer are retained by the authors and/or other copyright owners and it is a condition of accessing publications that users recognise and abide by the legal requirements associated with these rights.

\section{Takedown policy}

If you believe that this document breaches copyright please refer to the University of Manchester's Takedown Procedures [http://man.ac.uk/04Y6Bo] or contact uml.scholarlycommunications@manchester.ac.uk providing relevant details, so we can investigate your claim.

\section{open 2 Access}




\title{
Linking Power and Flow in Rotor-Stator mixers
}

\author{
T.P. John ${ }^{\mathrm{a}}$, J.S. Panesar ${ }^{\mathrm{b}, 1}$, A. Kowalski ${ }^{\mathrm{b}}$, T.L. Rodgers ${ }^{\mathrm{a}}$, C.P. Fonte ${ }^{\mathrm{a}, *}$ \\ ${ }^{a}$ School of Chemical Engineering and Analytical Science, The University of Manchester, \\ Manchester M13 9PL, UK \\ ${ }^{b}$ Unilever R $\mathcal{E}$ D, Port Sunlight Laboratory, Quarry Road East, Bebington, Wirral CH63 \\ 3JW, UK
}

\begin{abstract}
The relationship between power and flow characteristics of batch rotor-stator mixers has been studied using CFD simulations with experimental power validation. The mixer studied was the Silverson L5M batch mixer with the standard emulsor head. The size of the holes in the screen and the constriction of the base hole were changed in small increments. The MRF technique was used to model rotor rotation. A model is developed in this study which links the power and flow numbers of the mixer. Since power is easy to measure experimentally, one can use this model to predict the flow number by measuring torque. A second model is also developed which allows one to predict the flow number using solely the geometry of the mixing head. This study greatly enhances our understanding of the relationship between power, flow and mixer geometry in rotor-stator mixers.
\end{abstract}

Keywords: Rotor-stator. Mixing. Power number. Flow number. CFD.

${ }^{*}$ Corresponding author Email address: claudio.fonte@manchester.ac.uk (C.P. Fonte)

${ }^{1}$ Present address: CentDS Ltd, Nexus, Discovery Way, LS2 3AA, Leeds, UK. 


\section{Nomenclature}

\section{Symbols}

$\dot{m} \quad$ Mass flow rate

$\operatorname{kg} \mathrm{s}^{-1}$

B Empirical constant

$-$

C Empirical constant

$-$

$\mathrm{Po}_{1} \quad$ Power number constant

$-$

$\mathrm{Po}_{\mathrm{Z}}$ Power number constant

A Area

$\mathrm{m}^{2}$

a Empirical exponent

D Diameter

$\mathrm{m}$

F $\quad$ Fill ratio

$U_{Q} / U_{t i p}$

$H \quad$ Screen height

$\mathrm{m}$

$k \quad$ Empirical constant

$-$

$k_{1} \quad$ Empirical constant

$N \quad$ Rotor speed

$\mathrm{s}^{-1}$

$Q \quad$ Volumetric flow rate

$\mathrm{m}^{3} \mathrm{~s}^{-1}$

$R \quad$ Radius

$\mathrm{m}$

T Stator base thickness m

$U_{Q} \quad$ Average fluid velocity through stator holes $\mathrm{m} \mathrm{s}^{-1}$

$U_{t i p} \quad$ Rotor tip speed $\mathrm{m} \mathrm{s}^{-1}$

$v_{n} \quad$ Normal velocity $\mathrm{m} \mathrm{s}^{-1}$

\section{Greek symbols}

$\Delta$ Rotor-stator gap m m

$\Delta_{\text {row }}$ Vertical distance between row centres m

$\epsilon \quad$ Turbulent dissipation rate $\mathrm{m}^{2} \mathrm{~s}^{-3}$ 
$\epsilon_{\max }$ Maximum turbulent dissipation rate

$\mathrm{m}^{2} \mathrm{~s}^{-3}$

$\alpha \quad$ Empirical constant

$\beta \quad$ Empirical constant

$\rho \quad$ Density

$\mathrm{kg} \mathrm{m}^{-3}$

\section{Sub- and super-scripts}

b Stator base hole

$h \quad$ Screen holes

$i \quad$ Inner screen wall

$o \quad$ Outer screen wall

$r \quad$ Rotor

$s \quad$ Whole stator

\section{Dimensionless numbers}

$\mathrm{Eu} \quad$ Euler number

$$
\begin{array}{r}
\Delta p / \rho v^{2} \\
Q / N D_{r}{ }^{3} \\
Q / N D_{r}{ }^{3} \\
P / \rho N^{3} D_{r}{ }^{5}
\end{array}
$$$$
\mathrm{N}_{\mathrm{Q}, 0} \quad \text { Flow number at } A_{b}=0
$$

Po Power number

\section{Abbreviations}

CFD Computational Fluid Dynamics

MRF Multiple Reference Frame

PIV Particle Image Velocimetry 
1

2 3

4

\section{Introduction}

Rotor-stator mixers, also known as high shear mixers, are mixing devices consisting of high speed rotors surrounded by stationary screens, or stators. They are widely used for processes which require intense mixing such as deagglomeration and emulsification, since they generate very high shear rates in the region of the mixing head and also provide highly localised energy dissipation. For lab-scale operation, they are usually operated in a batch configuration, with the mixing head positioned on the end of a shaft which can be lowered into or raised from a mixing vessel. For larger scale processing, a continuous configuration is typically used, in which the mixing head is encased within a pipeline.

Despite their widespread use, there is a significant lack of theoretical understanding around rotor-stator mixers (Atiemo-obeng et al., 2004). In particular, there is a lack of understanding of how the design of the stator affects the agitation power and the hydrodynamics of the mixer. The agitation power is an important process variable, since it determines how much energy the mixer will use. It also provides valuable information related to the amount of energy available for droplet break-up during emulsification. Mechanistic models are available to predict the maximum droplet size during emulsification in the turbulent flow regime, which are based on the assumption that droplet break-up is caused by the interactions between the turbulent eddies and the dispersed droplets, and also that the droplets are larger than the smallest eddies at the Kolmogorov length scale (Calabrese et al., 1986; Davies, 1985, 1987; Hinze, 1955). One of the variables needed to predict the maximum droplet size is the maximum turbulent energy dissipa- 
tion rate, $\epsilon_{\max } . \epsilon_{\max }$ is particularly difficult to measure experimentally, and so instead the average energy dissipation around the impeller can be used. This means that

$$
\epsilon_{\max } \propto \operatorname{Po} N^{3} D_{r}^{2}
$$

where Po is the dimensionless power number for the impeller, $N$ is the rotational speed of the impeller, and $D_{r}$ is the diameter of the impeller (Carrillo De Hert, 2017). Po can be measured using experimental torque measurements, however, for standard impellers used in industry it is usually just found from literature. Obtaining Po for rotor-stators without using torque measurements is much more complex since there are many different designs of screen, each of which results in a different value of Po. It has been reported that droplet break-up in rotor-stators is caused by shear rather than turbulence (Rodgers and Cooke, 2012), in which case the above information regarding energy dissipation and droplet break-up models is not so relevant. In any case though, it is still highly desirable to understand how the screen design affects the agitation power. By doing so, it would therefore be possible to predict the power number based on the geometry of the mixing head, and so experimental torque measurements would not be required each time the screen design is changed. Optimisation of the screen design for emulsification processes would also be much easier with more knowledge in this area.

For in-line rotor stators with a given screen design, the power number has been found to be given by

$$
\mathrm{Po}=\mathrm{PoZ}_{\mathrm{Z}}+k_{1} \mathrm{~N}_{\mathrm{Q}}
$$


where $\mathrm{Poz}_{\mathrm{z}}$ is a constant which can be thought of as the power required to overcome the drag force as the rotor moves in the fluid, $k_{1}$ is a constant which depends on the mixing head geometry, and $\mathrm{N}_{\mathrm{Q}}$ is the dimensionless flow number of the mixer (Kowalski, 2009). $\mathrm{N}_{\mathrm{Q}}$ is calculated as follows

$$
\mathrm{N}_{\mathrm{Q}}=\frac{Q}{N D_{r}^{3}}
$$

where $Q$ is the volumetric flow rate. Equation (2) has been proven valid by both experimental means and simulation for many different designs of in-line mixer (Cooke et al., 2011; Hall et al., 2011; Kowalski et al., 2011; Özcan-Taşkın et al., 2011; Jasińska et al., 2015). Equation (2) has been applied for in-line mixers due to the fact that $\mathrm{N}_{\mathrm{Q}}$ can be measured and varied with ease, since the flow rate in an in-line mixer is essentially flow through a pipeline. No such model has been applied or tested by other authors for batch mixers since, for a given mixing head design, $\mathrm{N}_{\mathrm{Q}}$ can not easily be changed or measured. It has already been noted in literature that to investigate the effect of mixing head design on $k_{1}$ would be highly beneficial in the development of our understanding of these mixers (Håkansson, 2018). Padron (2001) studied power draw in various batch-rotor stator mixers, each with a different mixing head design, and concluded that the stator geometry, ie. number and size of holes in the screen did have an effect on the agitation power and therefore also the power number. However no correlation was found between stator geometry and power number. These conclusions are similar to many other studies which have also been conducted in this field of research (Utomo et al., 2008, 2009; Özcan-Taşkın et al., 2011; Mortensen et al., 2017). It is likely that no correlation has been found between the stator 


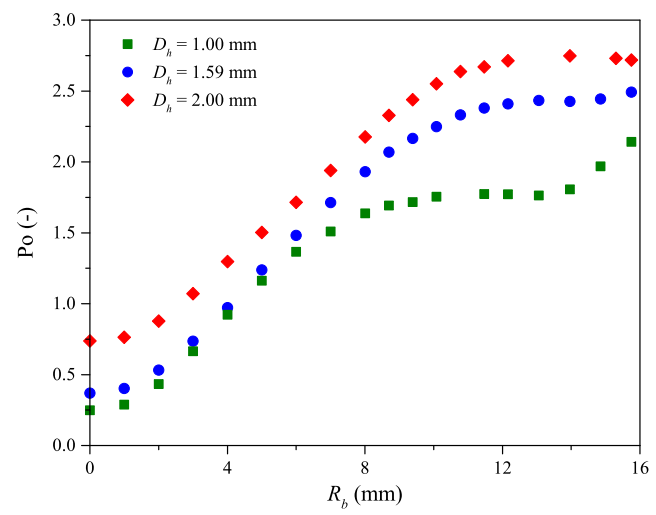

(a)

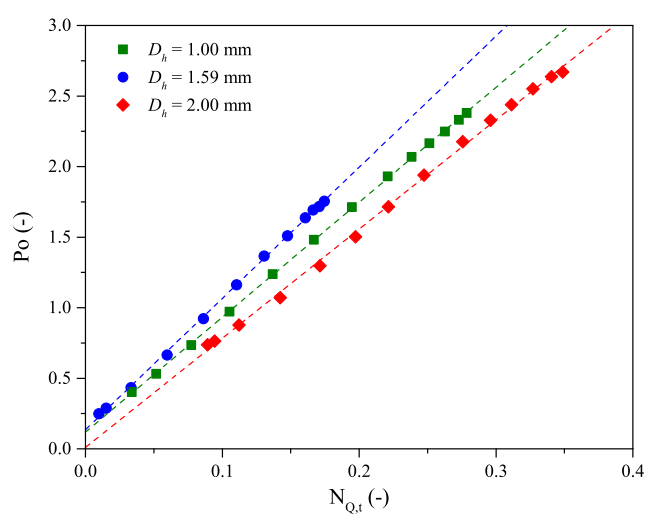

(b)

Figure 1: Power number against (a) base hole radius and (b) flow number predicted by CFD for the Silverson L5M with standard emulsor head and various hole sizes, taken from John et al. (2019).

geometry and the agitation power due to the fact that previous studies have, for the majority, been conducted using drastically different designs of mixing head for each experiment. Essentially, more than one geometrical variable is changing between designs. It would be much more beneficial to perform experiments in which only one geometrical parameter changes systematically.

John et al. (2019) studied power and flow in the Silverson L5M operating in both batch and in-line modes using CFD with experimental torque measurements used as validation. It was found that by changing the constriction of the base holes, $\mathrm{N}_{\mathrm{Q}}$ could be changed for a given screen design. The results also suggested that for the batch mixer, the power number could be predicted using the model typically used for in-line mixers shown in Equation (2), something which had not previously been explicitly suggested in literature. This is only the case when flow does not exit the base of the stator, something which will be explained in Section 3. It was suggested that the 
rise in power number at large base radiuses, as seen in Figure 1(a) is due to flow begining to exit through the base. Since the study was conducted in a systematic manner, with stator geometries differing only in small increments, the effect of screen design on the constant $k_{1}$ could be seen much more clearly than from previous studies. The effect of screen design on $k_{1}$ was explained using the Euler number, Eu, which is the ratio between pressure and inertial forces. The equation developed by Kowalski (2009) shown in Equation (2) was derived by considering the acceleration of the fluid by the rotor in the mixing head. John et al. (2019) showed that by instead considering the pressure drop created by the rotor, $k_{1}$ in Equation (2) can be replaced with Eu. It is also recorded in literature that for fluid flowing through a perforated plate in a pipe, Eu is dependent on the design of the holes (Malavasi et al., 2012), which potentially explains why the screen design affects $k_{1}$ in a rotor-stator mixer.

The aims of this study were to investigate how the stator geometry affects agitation power in batch rotor-stator mixers. In this study, stator geometries are changed in small systematic increments in order to enhance our understanding of which geometrical parameters affect the power and flow characteristics.

\section{Materials and Methods}

\subsection{Stator geometries}

The rotor-stator mixer used in this study was the Silverson L5M batch lab-scale mixer. There are various designs of stator for this mixer, including the disintegrating head, slotted head, square hole head, and the standard emulsor head. The standard emulsor head was used as the stator design in 
this study. The standard emulsor head consists of staggered rows of small closely spaces circular holes (see Figure 3).

As previously mentioned, $\mathrm{N}_{\mathrm{Q}}$ is not easily changed in a batch rotor-stator with a given stator design due to the fact that the speed and the diameter of the rotor both affect the flow rate, ie. the flow rate can not be varied independently using the rotor. To vary the flow rate of a particular screen design, the hole in the base of the stator can be constricted. This has a similar effect on the flow rate as when one uses a valve to change the flow in an in-line mixer. The constriction of the base hole can be seen in Figures 3(d) and 3(e). As can be seen from Figure 3 and Table 1, the base hole was varied from fully open, $3(\mathrm{a})$, to fully closed, $3(\mathrm{e})$. The effect of varying $\mathrm{N}_{\mathrm{Q}}$ by changing the base hole size on agitation power was investigated for screens with various hole sizes, as can be seen in Figure 3. Figures 3(a), 3(b), and 3 (c) show stators with the same number of holes but different sized holes. Figures 3(f) and 3(g) show stators with the same total area of holes as Figure 3(a), but with different sized holes, ie. the number of holes was varied to keep the area roughly constant. These experiments were designed to allow us to determine whether it is simply the area of the holes which affects $k_{1}$ or whether it is something more complex such as the hydraulic radius of the holes. The dimensions of the stator defined in this investigation are shown in Figure 2. Table 1 lists range of values of the stator dimensions used in this study. 


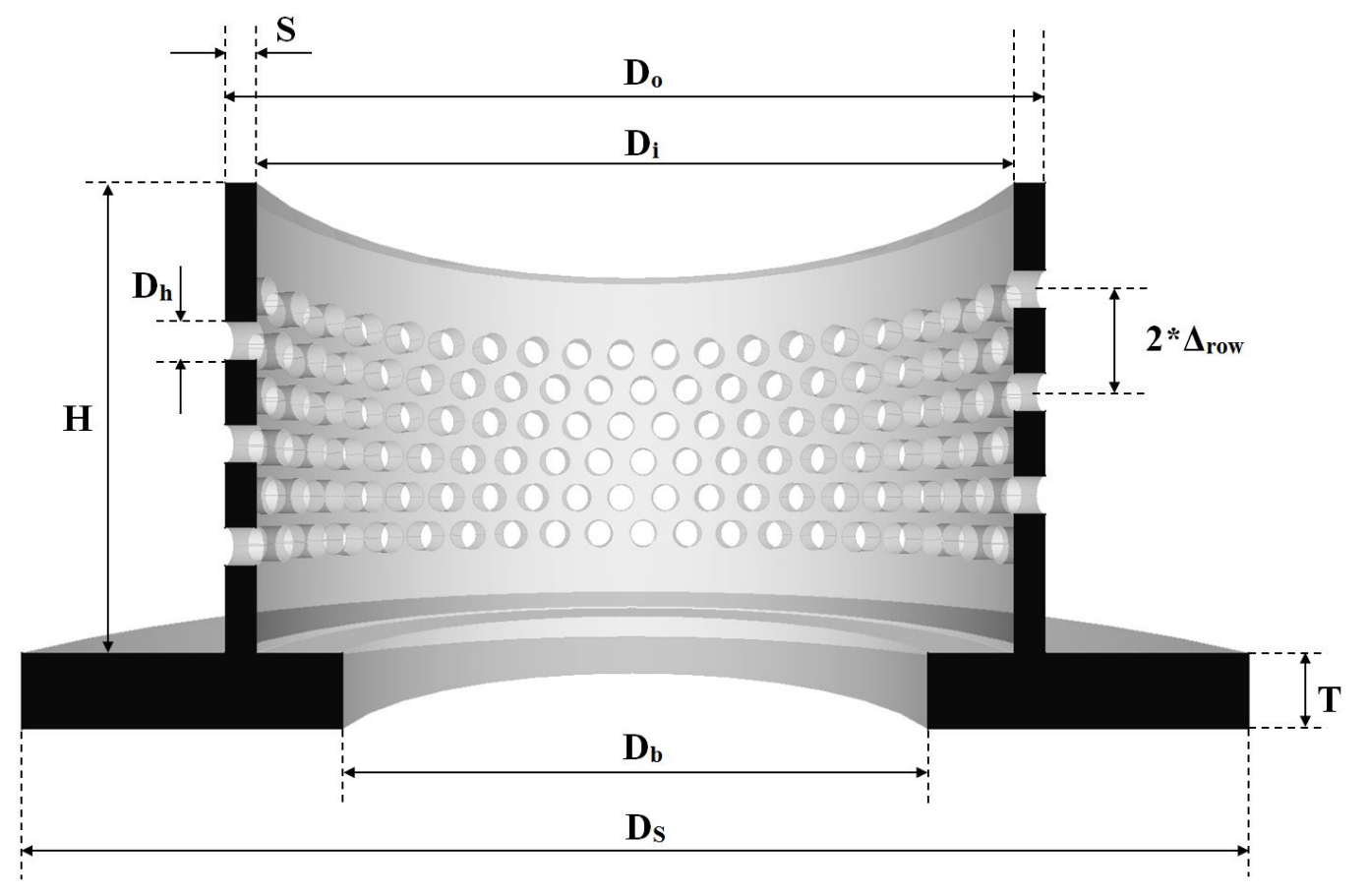

Figure 2: General stator dimensions. 
Table 1: Range of values of stator dimensions used in this investigation. All values given for standard scale simulations.

\begin{tabular}{ccc}
\hline Symbol & Meaning & Values $(\mathrm{mm})$ \\
\hline$D_{b}$ & Base hole diameter & $0 \leq D_{b} \leq 31.50$ \\
$D_{h}$ & Screen hole diameter & $1.00 \leq D_{h} \leq 2.00$ \\
$D_{i}$ & Inside screen diameter & 31.50 \\
$D_{o}$ & Outside screen diameter & 34.10 \\
$D_{s}$ & Whole stator diameter & 51.00 \\
$H_{s}$ & Screen height & 19.55 \\
$S$ & Screen thickness & 1.25 \\
$T$ & Base thickness & 3.15 \\
$\Delta_{\text {row }}$ & Vertical distance between row centres & $2.14 \leq \Delta_{\text {row }} \leq 2.50$ \\
\hline * note that for simulations run at different scales, all values of all dimensions are just \\
scaled by the factor chosen.
\end{tabular}

The rotor used was a 4 bladed rotor in all cases. The rotor for the standard scale simulations, where $T=0.24 \mathrm{~m}$, was $31 \mathrm{~mm}$ in diameter, and $12.5 \mathrm{~mm}$ in height. The centre of the rotor was always positioned vertically at the centre of the stator. This ensured, at least for most simulations, that all the rows of holes remained fully covered by the rotor. 


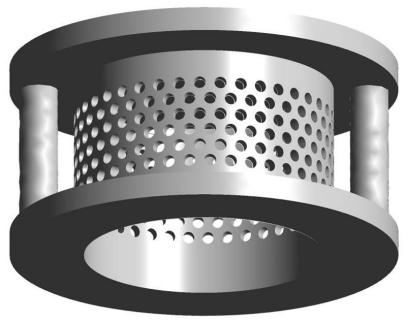

(a)

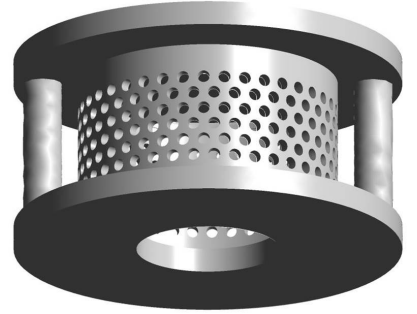

(d)

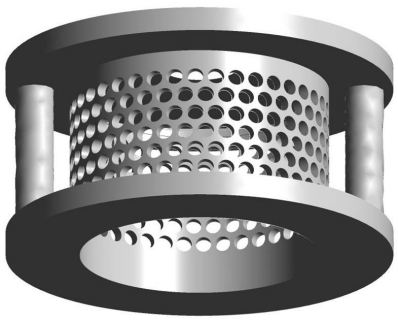

(b)

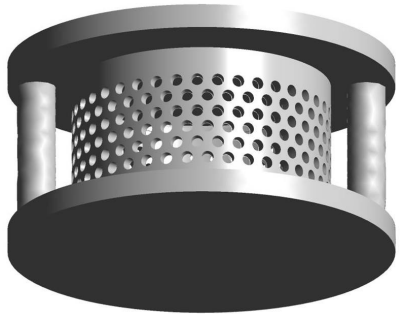

(e)

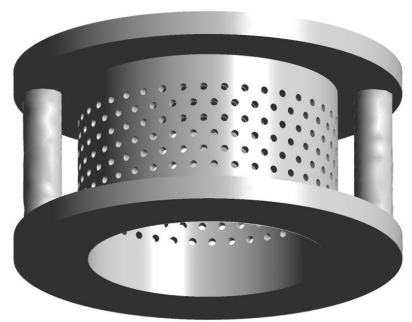

(c)

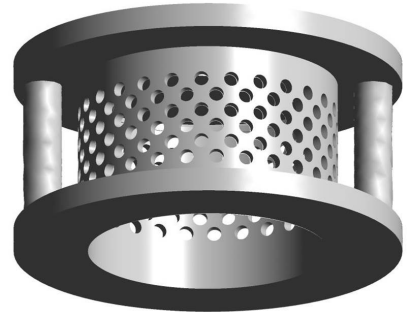

(f)

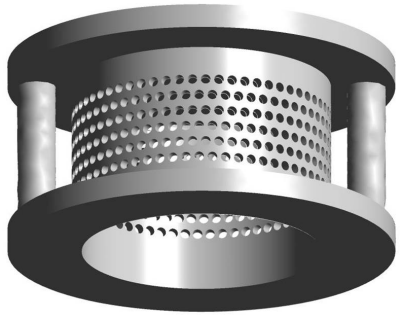

(g)

Figure 3: Examples of stator geometries.

\subsection{CFD model}

CFD simulations were carried out using ANSYS Fluent version 18, with each simulation being run on 12 cores. To model the rotation of the rotor one can either use the transient sliding mesh technique or the steady-state multiple reference frame technique. Sliding mesh has previously been the most popular choice for CFD simulations of rotor-stator mixers due to the fact that transient simulations are needed to account for the time dependent interaction between the rotor and the stator holes. This time dependency 
is more pronounced with some stator designs than others. For example, the Silverson disintegrating head causes a large time dependency due to the fact that the holes are very large, relatively speaking, and spaced very sparsely. As mentioned, the stator used in this study is the standard emulsor head, which has small holes which are closely spaced and staggered between rows. This means that the time dependent fluctuations in power and flow will be very small and therefore the MRF technique can be used, which saves a large amount of simulation time and computational expense. To prove that the MRF technique is sufficient for this design, multiple rotor simulations were tested. The interaction between the rotor and the baffles can be assumed to be negligible since a rotor-stator naturally dissipates energy in a small region around the mixing head, and the distance between the rotor and the baffles is relatively large.

Turbulence was modelled using the standard $k-\epsilon$ model, which has been widely used for the simulation of rotor-stator mixers (Håkansson et al., 2017; Jasińska et al., 2015; Minnick et al., 2018; Mortensen et al., 2018; ÖzcanTasskin et al., 2011; Utomo et al., 2008, 2009). All constants in the $k$ and $\epsilon$ transport equations were left as their default values, and the standard wall function was employed to model near-wall viscosity-dependent effects. This combination of model and wall function was found to give the best agreement between the agitation power predicted from torque on the rotor and shaft and the power predicted from the turbulent dissipation. To follow from this, power was always calculated using the torque on the rotor and the shaft. This method is more reliable and accurate than taking the volume integral of $\epsilon$, since all RANS turbulence models inherently under-predict turbulent 
dissipation (Rielly and Gimbun, 2009). All solid boundaries were given the no-slip condition whilst the shear stress at the free surface was specified as 0 in all directions. For spacial discretisation of the convective flow terms, the third order MUSCL scheme was used for momentum and turbulence, and the PRESTO! scheme was used for pressure. The COUPLED solver was used for the coupling of the pressure and the velocity.

The flow rate used in the calculation of the flow number, Equation (3), was taken at the inside wall of the stator. Flow through the holes was calculated by integrating the radial velocity across the inside wall of the screen, ie on a cylindrical surface with center at the center of the rotor and a radius of $15.75 \mathrm{~mm}$. The flow through the base of the stator was calculated by integrating the axial velocity across a circular surface at the top of the base hole, ie. on a circular surface with center at the center of the stator and a height of $3.15 \mathrm{~mm}$ which is the thickness of the base of the stator. The flows into (+ve) and out of (-ve) the mixing head can then be calculated as follows

$$
\begin{aligned}
Q_{+v e} & =\frac{\iint_{S}\left|v_{n}\right| \mathrm{d} S+\iint_{S} v_{n} \mathrm{~d} S}{2} \\
Q_{-v e} & =\frac{\iint_{S}\left|v_{n}\right| \mathrm{d} S-\iint_{S} v_{n} \mathrm{~d} S}{2}
\end{aligned}
$$

where $v_{n}$ is the velocity normal to the surface across which flow is being calculated, ie. radial for the holes and axial for the base.

Convergence was said to be reached when the torque on the rotor and the flow through the stator holes did not change with regards to the iteration 
number.

\subsection{Experimental procedure}

Experimental torque measurements were used to validate the power number predicted by the CFD simulations. The experimental procedure followed to measure the power in this study is identical to that described in the study by John et al. (2019). Experimental validation of the flow number predicted by our CFD simulations of batch rotor-stators is very difficult to obtain, since even with techniques such as 2D-PIV one must make various assumptions relating to the way that the flow changes throughout each hole or slot in the screen. This is relatively simple for stators with rectangular slots such as the slotted head Mortensen et al. (2011), however it is much more difficult for stators with circular holes such as the stator used in this study, especially since the flow is also found to vary in-between the rows of holes (this will be discussed in Section 3). Realistically it is only possible to accurately validate velocity profiles rather than the whole flow rates. For this reason, experimental validation was only carried out for the power number.

\section{Results and discussion}

Results regarding the validation of the CFD model can be found from the study of John et al. (2019). These results include the comparison between the predicted power number from CFD and the experimental one, the effect of grid refinement on the CFD results (ie, the establishment of grid independent results), and also the effect of rotor position on power and flow numbers. The results presented from here on in are presented under the assumption that the CFD model used is now well validated. 
Radial velocity/Tip speed [-]

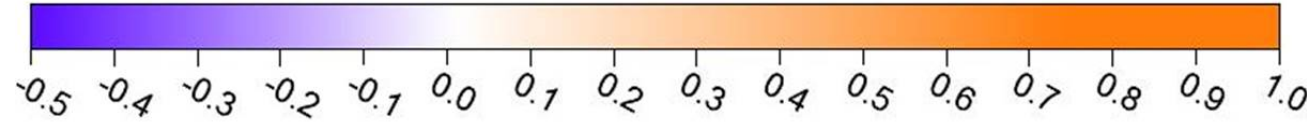

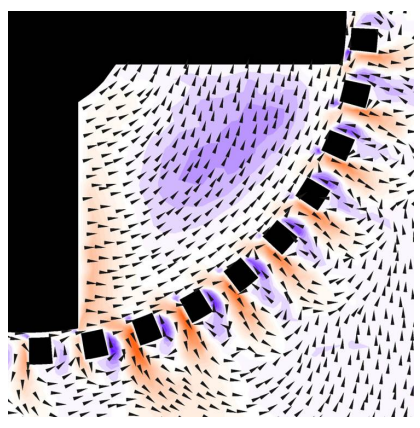

(a) Row 1.

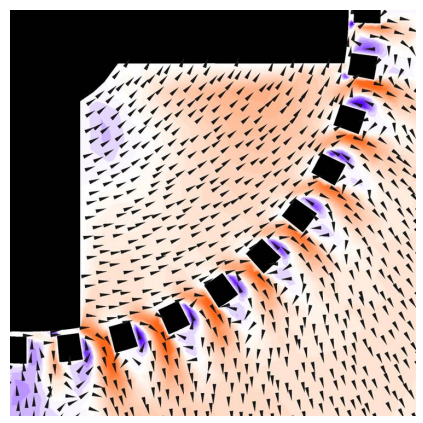

(d) Row 4.

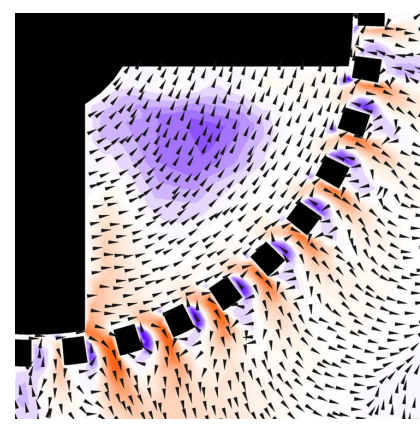

(b) Row 2.

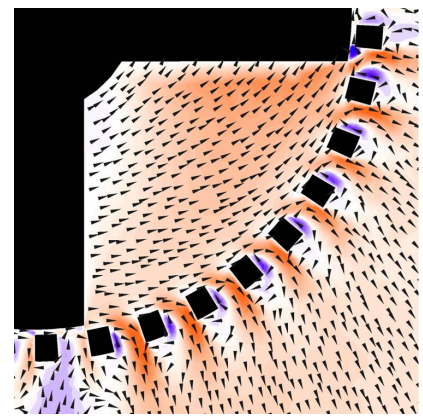

(e) Row 5.

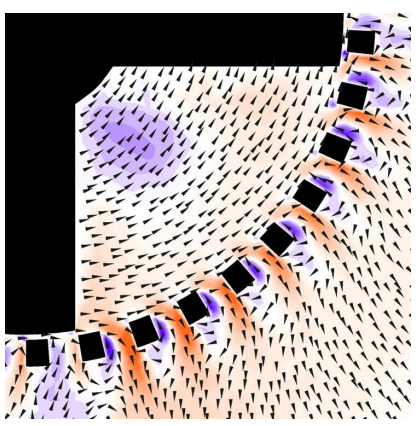

(c) Row 3.

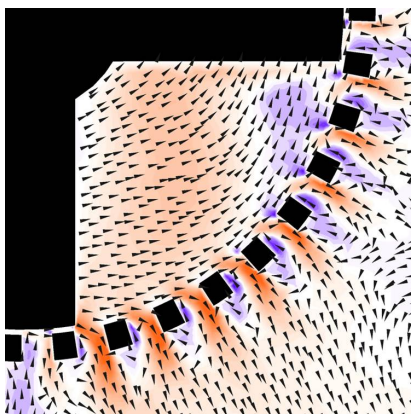

(f) Row 6.

Figure 4: Contours showing the radial velocity normalised by the rotor tip speed on 6 planes at the heights of the 6 rows of holes in the screen. Velocity vectors are overlapped to show the direction of flow. Stator is the original standard emulsor head from Silverson.

Figure 4 shows the radial velocity normalised by the tip speed of the rotor at planes of heights equal to the center of each row of holes. Each velocity contour is very similar to those obtained previously by both experimental means and CFD simulations, in that on the leading edge of each hole there is a high velocity jet which extends from the inside of the hole to the bulk of the tank, and behind this the fluid recirculates back into the hole towards 
the rotor swept region (Utomo et al., 2008; Mortensen et al., 2011). The maximum normalised radial velocity reached is, quite understandably, close to unity and the highest radial velocities reached generally are located in the high velocity jets on the leading edge of the holes. It can also be seen from these results that the velocity contour is different for each row of holes in the screen, more specifically the flow appears to become more positive from rows 1 to 5 and then drop slightly at row 6 . Figure 5 shows the mass flow rate of the positive radial component leaving the holes against row number (Figure 5(a)) and also the mass flow rate of the negative radial component recirculating back into the holes against row number (Figure 5(b)). These results show, quantitatively, the information displayed in Figure 4. The results suggest that there is not only non-uniformity in the flow rates across the various rows of holes, but also that this non-uniformity actually increases as the size of the holes in the screen increases. For the $2.00 \mathrm{~mm}$ holes, the flow through the lowest and highest rows appears to be quite extreme, that is there is a large amount of flow entering the lowest row and a small amount of flow exiting the top row relative to the other hole sizes. This could be due to the fact that for this particular hole size, the rotor doesn't entirely cover the top and bottom rows of holes. Similar results to this have been found by Espinoza et al. (2018), who used particle image velocimetry (PIV) to study the flow field of an in-line Silverson mixer. They also concluded that the flow was non-uniform across the rows of holes in the stator screen. 


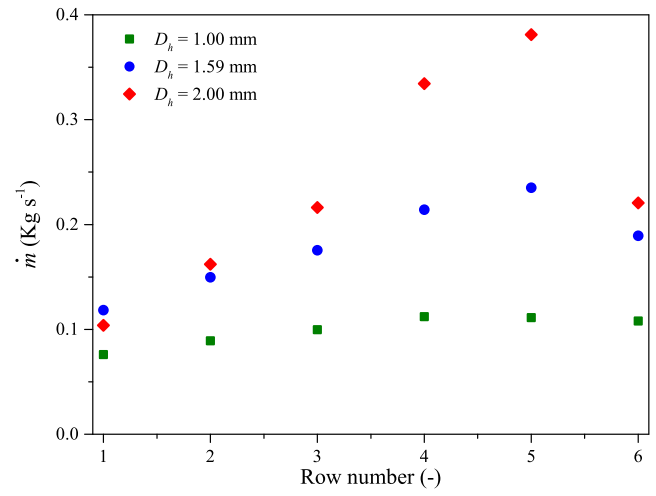

(a)

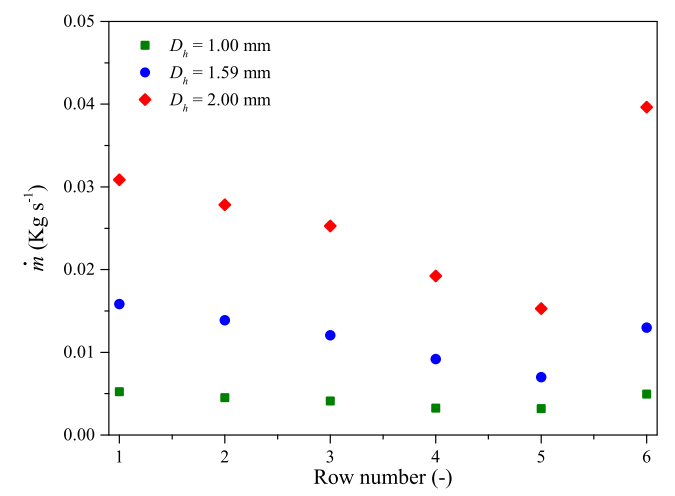

(b)

Figure 5: Mass flow rates (a) out of and (b) into each of the rows of holes, with 1 being the lowest with regards to the y-axis, for various sizes of holes in the screen of the stator. 


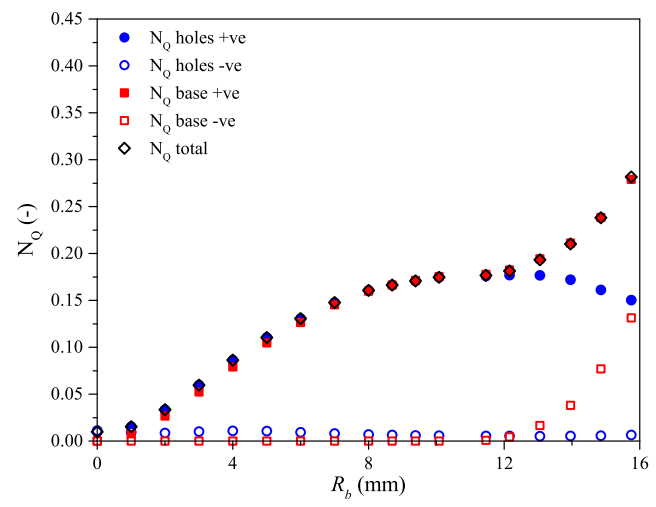

(a)

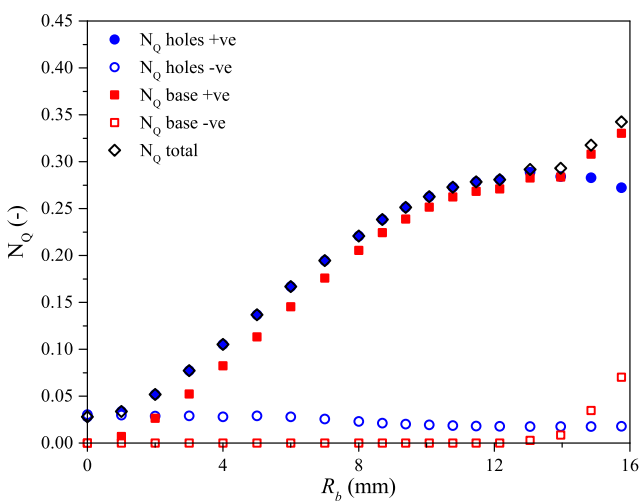

(b)

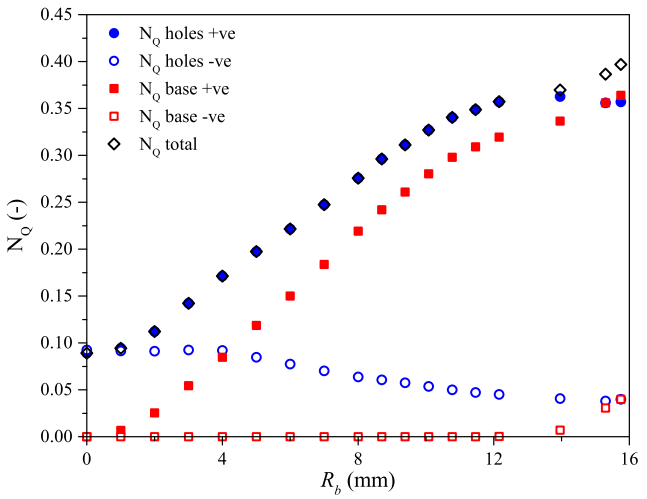

(c)

Figure 6: Flow number components against base hole radius for screens with holes sizes of (a) $1.00 \mathrm{~mm}$, (b) $1.59 \mathrm{~mm}$, and (c) $2.00 \mathrm{~mm}$.

Figure 6 shows each component of the flow number as a function of the base hole radius for screens with holes of various sizes. It is useful here to mention that the total flow number can be calculated as either the sum of the total inwards flow into the mixing head $\left(\mathrm{N}_{\mathrm{Q}}\right.$ holes -ve and $\mathrm{N}_{\mathrm{Q}}$ base + ve) or as the sum of the total outwards flow out of the stator $\left(\mathrm{N}_{\mathrm{Q}}\right.$ holes + ve and $\mathrm{N}_{\mathrm{Q}}$ base -ve). Theoretically both of these these should give the exact same total 
$\mathrm{N}_{\mathrm{Q}}$, however since CFD is a numerical approach, convergence issues may give rise to slight discrepancies. For each screen hole size, the total flow number appears to follow a similar trend, that is an increase in flow number as the base hole begins to open followed by a plateau and then another increase as the base hole becomes fully open. This trend is similar to that of the power number as shown in Figure 1(a), which is expected since Figure 1(b) suggests that $\mathrm{Po} \propto \mathrm{N}_{\mathrm{Q}}$. The trend of the total flow number can be explained using each of the flow number components. The total flow number increases as the base begins to open due to the fact that the flow enters through the base and exits through the holes in the screen. The amount of flow entering through the holes in the screen also contributes to this total flow number, hence why the total flow number is generally larger for screens with larger holes. This also explains why, for $D_{h}=2.00 \mathrm{~mm}$, there is a much larger total flow number at $R_{b}=0$. The increase of the total flow number after the plateau has been reached appears to be caused by flow exiting the base. Barailler et al. (2006) used CFD to simulate a batch rotor-stator mixer and also found that with a fully open base there was flow leaving the mixing head through the base of the stator. From Figure 6 it can be seen that this behaviour is more prolific for screens with smaller holes, likely since there is less area for the fluid to leave through the holes, and so the total flow rises more sharply after the plateau when the holes in the screen are smaller. This was also suggested by Barailler et al. (2006). The explanation as to why the plateau occurs will be given later on in this section.

As previously mentioned, it is likely that $k_{1}$ can be replaced with Eu which is affected by the size of the holes in the screen. It is unknown whether it 


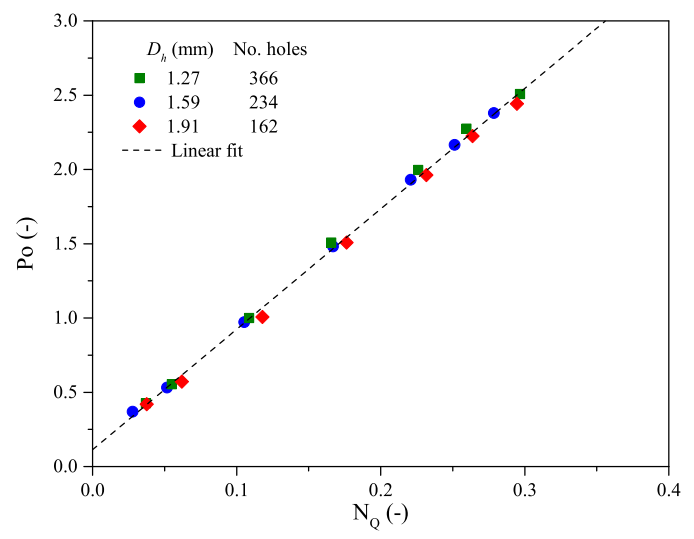

Figure 7: Power number as a function of flow number for stators with fixed $A_{h}$ but varying $R_{h}$.

would likely be the area of the holes, $A_{h}$, or the hydraulic radius of the holes which affects $k_{1}$. Figure 7 shows the power number as a function of the flow number for three stators whose hole size varies but total area of holes is constant. The results suggest that $k_{1}$ is not affected by the hydraulic radius of the holes but the total area of the holes. This conclusion can only be made for changes in hole size similar to that investigated in this study. Further changes in hole size were not investigated in this study as the increased fluctuations in power and flow would require transient simulations, or at least multiple steady state simulations with varying rotor positions. Mortensen et al. (2017) conducted a similar study with a slotted head stator and found that the hydraulic radius did affect the flow number of this mixer for a certain range of slot widths, but also didn't affect the flow number in another range of slot widths. It would make sense that the flow number is somewhat affected by the hydraulic radius of the stator holes, since the high velocity jets form on the leading edge of the stator holes. For stators with the same total hole area, a larger hydraulic radius means that the perimeter 
of the holes is smaller and hence there is less room for the high velocity jets to form. It might also be the case that the area of the holes has an individual effect on the flow number, since it has been shown in the study of Malavasi et al. (2012) that for a perforated plate in a pipe, there are multiple terms used in the calculation of the Euler number, some of which are purely area effects. It is therefore evident that to truly understand how the area and the hydraulic radius of the holes affects flow characterisation in rotor-stator mixers is highly complex. Using all of the previous information, we propose here that for the stators used in this study

$$
\mathrm{Eu}=k\left(\frac{A_{h}}{D_{r}{ }^{2}}\right)^{a}
$$

where $k$ is a pre-exponential empirical constant and $a$ is an empirical exponent. It was also found that $\mathrm{Poz}_{\mathrm{z}}$ followed a similar trend so that

$$
\mathrm{Po}_{\mathrm{Z}}=\mathrm{Po}_{1}\left(\frac{A_{h}}{D_{r}{ }^{2}}\right)^{a}
$$

where $\mathrm{Po}_{1}$ is another pre-exponential constant. Figure 8 shows all of the data obtained in this study collapsed using Equations (6) and (7). It can be seen that all of the data fits onto the correlation almost perfectly with an $r^{2}$ value of 0.996 . The power number for a batch rotor-stator with a standard emulsor head can therefore be predicted using the following

$$
\frac{\mathrm{Po}_{\mathrm{O}}}{\left(\frac{A_{h}}{D_{r}{ }^{2}}\right)^{a}}=\mathrm{Po}_{1}+k \mathrm{~N}_{\mathrm{Q}}
$$

for various hole sizes. 
Of course, it would be ideal to be able to predict the power number not just for stators of a particular design, but many designs. Figure 9 shows data obtained from CFD simulations of a Silverson L4M with various stator designs, namely the slotted head, disintegrating head, and square hole head from Utomo et al. (2008), and also data from PIV experiments on a custom built mixer with a slotted head stator from Mortensen et al. (2017). The correlation proposed in Equation (8) is compared with the data for other studies in Figure 9. It can be seen that the correlation appears to work for not just the standard emulsor head, but many designs of stator. This may seem contradictory to some of the previous conclusions in this study. It has been mentioned that only stators with no negative axial flow in the base were considered for the data analysis. Stators with fully open bases sometimes exhibit axially negative flow in the base, and the magnitude of this depends on the size of the holes in the screen. It is therefore likely that the areas of the holes in the stators used in the studies by Utomo et al. (2008) and Mortensen et al. (2017) were large enough so that there was little or no negative axial flow through their bases. The results from the study of Mortensen et al. (2017) also provide some validation to our CFD results since they are experimental PIV results.

The results from Figures 8 and 9 are particularly useful, since they also suggest that it is possible to predict the flow number for a batch rotorstator using the power number, which can be measured easily using torque measurements. It is far easier and simpler to measure the power in a batchrotor stator than it is to measure the flow rate, especially since it has already been shown in this study and the study of John et al. (2019) that the flow 
which needs to be measured is the actual flow through the holes in the screen, not just the flow in the pipe in the case of the in-line mixer.

The results from John et al. (2019) suggested that for a given screen design, a batch and in-line mixer share the same characterisation for power and flow, ie. $k_{1}$ and $\mathrm{Poz}_{\mathrm{z}}$ are the same. This would also mean that Equation (8) should work for multiple stator geometries regardless of mode of operation. A correlation was developed in John et al. (2019) which allowed the prediction of the true flow rate through the holes in the screen based on the geometry of the stator. Therefore, for an in-line mixer, Po can be predicted using only the geometry of the stator.

It should be noted here that all of the mixers investigated in this study are single rotor/single stator mixers. It is likely the same conclusions can not be made for mixers with more than one rotor or stator. 


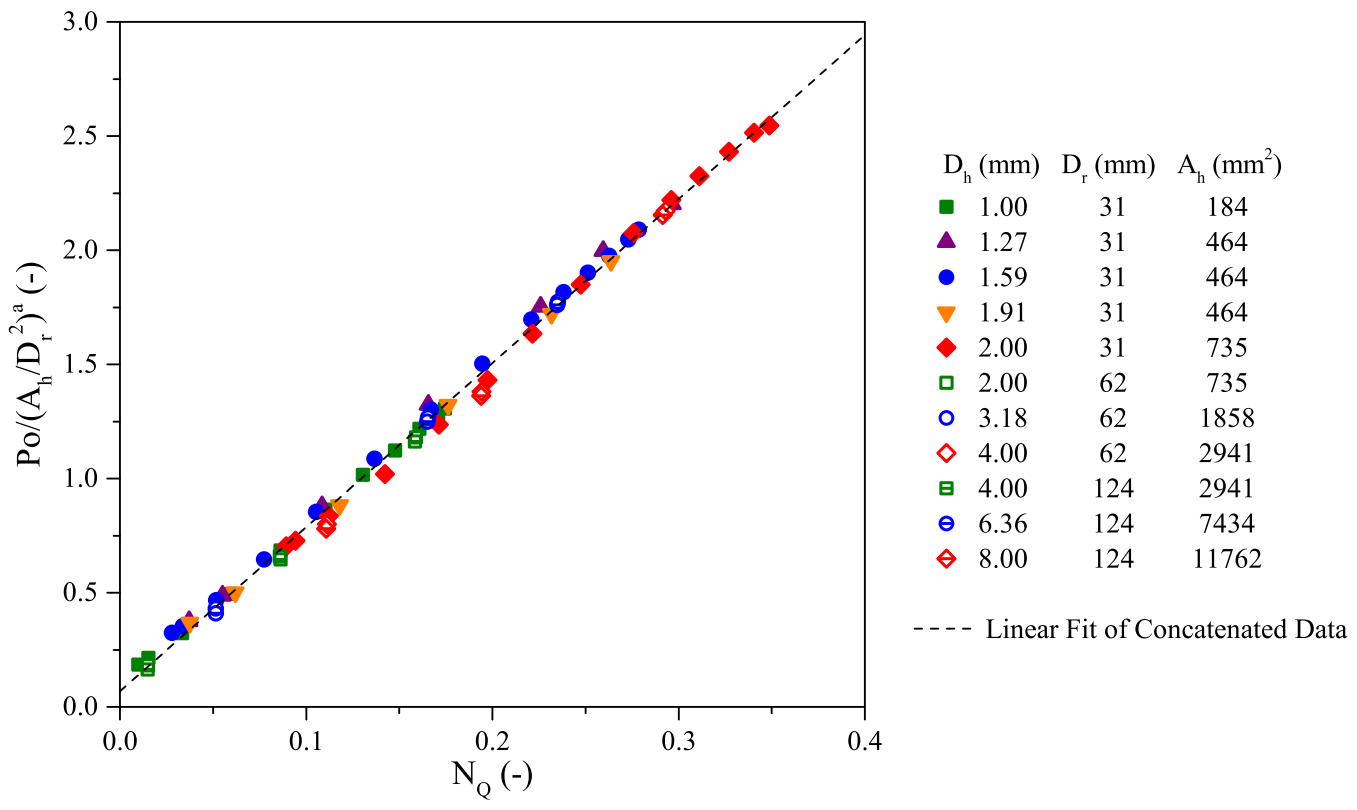

Figure 8: Plot showing how Equation (8) can be used to predict power number for a given flow number for multiple stator geometries.

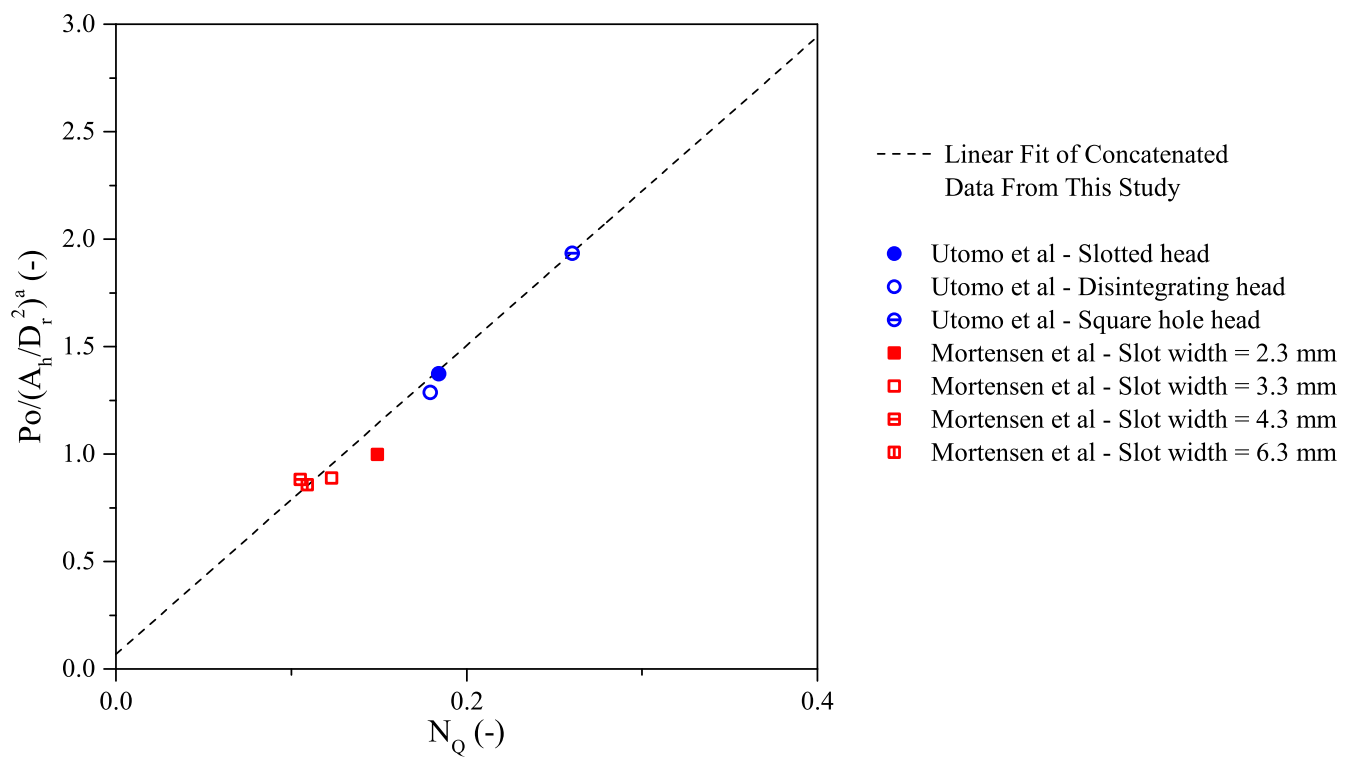

Figure 9: Plot showing how data from previous experimental and simulation based studies using dramatically different stator designs compare with the results presented in this study. 


\subsection{Prediction of flow number}

Although Equation 8 now allows us to predict the power number using the mixer geometry and the flow number, there is still no way of easily knowing the flow number in a batch rotor-stator. As already mentioned, the power can be measured using a torque meter and Equation (8) can be used to predict the flow number, but it would be more useful to be able to predict the flow number without having to run any experiments. Using the data from this study, we can propose a new correlation which allows us to also predict the flow number based on the mixer geometry. It must be noted here that this correlation only will work for stators who fall on the linear correlation shown in Equation (2), or more specifically, only for mixers who do not exhibit any axially negative flow through the base of the stator. These stators with negative flow through the base were ignored here as it is not yet understood whether this type of flow has an effect on the effectiveness of the rotor-stator in terms of emulsification. It could potentially be found that for optimal performance, stators should be constricted to prevent negative flow through the base. 


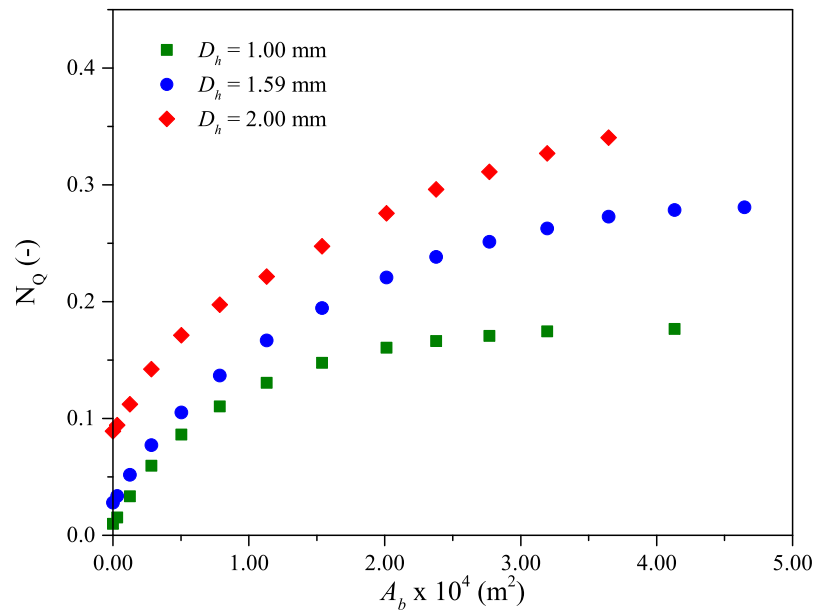

Figure 10: Flow number as a function of the area of the base hole for various screen hole sizes.

Figure 10 shows the flow number as a function of the area of the base hole for three different screen hole sizes. It can be seen that at low base hole areas, the flow number is proportional to the area of the base. This would be expected since the base hole is restricting the flow. At higher base hole sizes, the flow number begins to level off to a plateau since the holes in the screen are now restricting the flow and for a given hole size, the area of the holes is constant. If the flow through the holes was plug flow, it would be possible to predict the height of the plateau using the tip speed of the rotor and the area of the holes. However, as already mentioned, the high speed jets in the holes do not occupy the total area of the holes. It is therefore necessary to study how much of total area of the holes is actually taken up by the jets and how this changes with hole size. To achieve this, the fill ratio of the rotor stator will be used. The fill ratio is calculated using 


$$
F=\frac{U_{Q}}{U_{t i p}}=\frac{Q / A_{h}}{\pi N D_{r}}
$$

where $F$ is the fill ratio, $U_{Q}$ is the average radial velocity through the stator holes, $U_{t i p}$ is the tip speed of the rotor, and $Q$ is the volumetric flow rate of fluid in the high velocity jets. The fill ratio has been used in previous rotor-stator studies to investigate hydrodynamic differences between batch and in-line configurations (Mortensen et al., 2017). Figure 11 shows the fill ratio as a function of the area of the holes for various stators investigated in this study. The stators here are stators who exist on the plateaus shown in Figure 10, ie the holes in the screen are restricting the flow, not the base hole. It can clearly be seen that fill ratio is proportional to $A_{h}{ }^{-1 / 2}$. This tells us that as we increase the size of the holes, less of the area of the holes is actually used for the radial flow generated by the mixer. It is likely that the hydraulic radius of the holes, which takes into account the wetted perimeter of the holes, will have an impact on this relationship. The effect of hydraulic radius on mixer hydrodynamics was investigated in this study (see Figure 7), however the hole size could only be varied by relatively small amounts due to the fact that MRF was used in this study. Of course, one could create a stator with a very small number of very large holes, which would have the same area as the stators used in this study, but then periodicity in power and flow would require transient simulations. One would expect that for stators with a very large number of very small holes, the fill ratio would be nearer to unity than for stators with a small number of large holes. Ergo, the hydraulic radius of the holes in the screen should be considered when extreme changes in stator geometry are compared. 


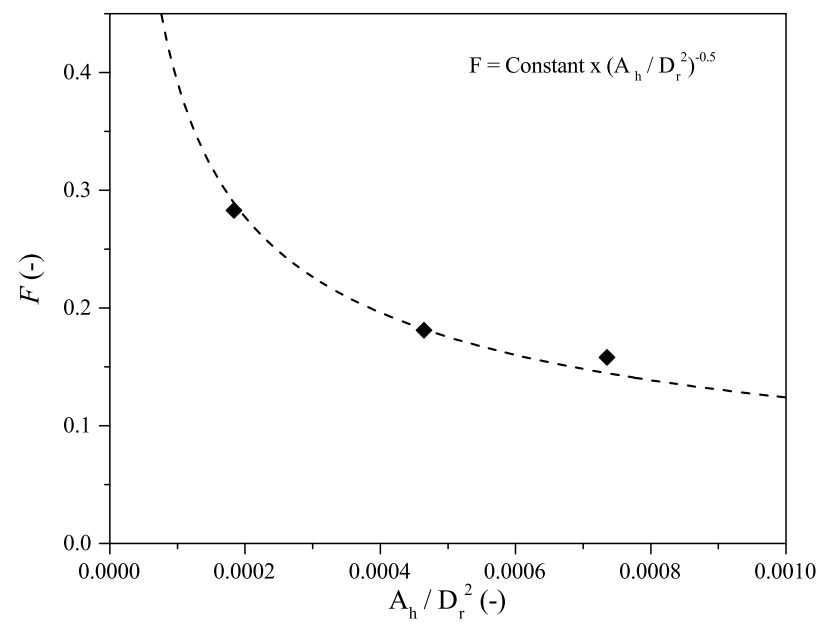

Figure 11: Fill ratio as a function of $A_{h} / D_{r}{ }^{2}$ for stators with hole sizes of $1.00 \mathrm{~mm}$, $1.59 \mathrm{~mm}$, and $2.00 \mathrm{~mm}$. Dotted line is a power law fit with exponent of $-1 / 2 . r^{2}=0.95$.

Using Equation, (9), it is now possible to know the level of the plateau relative to the flow number at a base hole area of 0 . At a base hole area of 0 , it can be seen that stators with larger holes have a higher flow number since all of the flow is entering and leaving through the holes. This flow number, $\mathrm{N}_{\mathrm{Q}, 0}$ can therefore be calculated by

$$
\mathrm{N}_{\mathrm{Q}, 0}=\mathrm{B} \frac{A_{h}}{D_{r}{ }^{2}}
$$

where B is an empirical constant. Using Equations (9) and (10) it is now possible to know the height of the plateau for each stator. Again, if flow through the holes in the screen were plug flow, the base hole area at which the plateau occurs would be equal to the area of the holes in the screen, and so to predict the flow number for all geometries the ratio of the base hole area and the total screen holes area could be used. Using the fill ratio again, we can account for the deviation caused by the low fill ratio. Figure 12 shows 

and Equation (10).

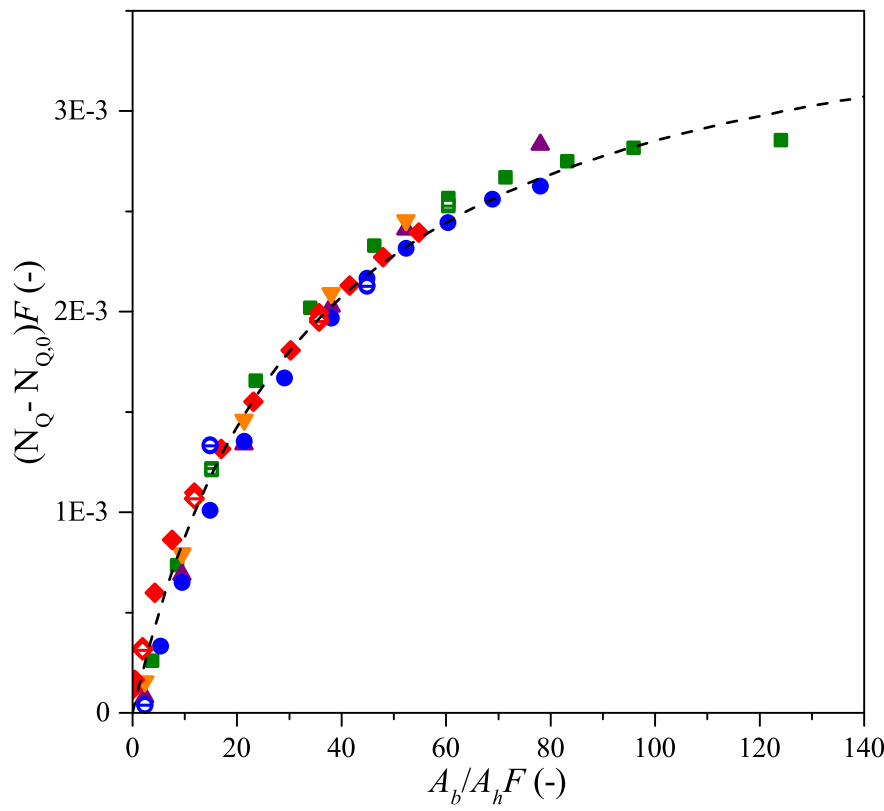

$\mathrm{D}_{\mathrm{h}}(\mathrm{mm}) \quad \mathrm{D}_{\mathrm{r}}(\mathrm{mm}) \mathrm{A}_{\mathrm{h}}\left(\mathrm{mm}^{2}\right)$

- $1.00 \quad 31 \quad 184$

\begin{tabular}{rr}
$1.27 \quad 31 \quad 464$ \\
\hline
\end{tabular}

- $1.59 \quad 31 \quad 464$

$\nabla$\begin{tabular}{lll}
$1.91 \quad 31 \quad 464$ \\
\hline
\end{tabular}

$2.00 \quad 31 \quad 735$

$2.00 \quad 62 \quad 735$

○ $3.18 \quad 62 \quad 1858$

$\diamond 4.00 \quad 62 \quad 2941$

$4.00 \quad 124 \quad 2941$

$\begin{array}{llll}\ominus & 6.36 & 124 & 7434\end{array}$

$\diamond 8.00 \quad 124 \quad 11762$

- - Y $=0.00011 \mathrm{X} *(1+0.03 \mathrm{X})^{-1}$

Figure 12: Curves from Figure 10 collapsed using Equations (9) and (10). Dotted line shows line of best fit whose format is displayed in the figure.

412

The flow number of a batch rotor stator can therefore be calculated using the following

$$
\mathrm{N}_{\mathrm{Q}}=\frac{\mathrm{B}\left(\frac{A_{h}}{A_{b} F}\right)}{1+\mathrm{C}\left(\frac{A_{h}}{A_{b} F}\right)} \times \frac{1}{F}-\beta\left(\frac{A_{h}}{D_{r}^{2}}\right)
$$

where $\mathrm{B}, \mathrm{C}$, and $\beta$ are empirical constants. Equation (11) can be rearranged using the results displayed in Figure 11 to give the following 


$$
\mathrm{N}_{\mathrm{Q}}=\frac{\mathrm{B}\left(\frac{A_{b}}{\alpha \sqrt{A_{h}} D_{r}}\right)}{\frac{\alpha D_{r}}{\sqrt{A_{h}}}+\frac{\mathrm{C} A_{b}}{A_{h}}}+\beta\left(\frac{A_{h}}{D_{r}{ }^{2}}\right)
$$

${ }_{416}$ where $\alpha$ is a fitting constant. The values of the fitting constants can be seen 417 in Table 2.

Table 2: Values of fitting constants used in Equation (12)

\begin{tabular}{cc}
\hline Constant & Value \\
\hline $\mathrm{B}$ & 0.00011 \\
$\mathrm{C}$ & 0.03 \\
$\alpha$ & 0.008 \\
$\beta$ & 0.1 \\
\hline
\end{tabular}

${ }_{418} \quad$ Figure 13 shows the flow number calculated from the CFD data in this 419 study against that predicted by Equation (12). It can be seen that Equation ${ }_{420}$ (12) is able to accurately predict the flow number in a batch rotor-stator 421 with a standard emulsor head for various geometries. 


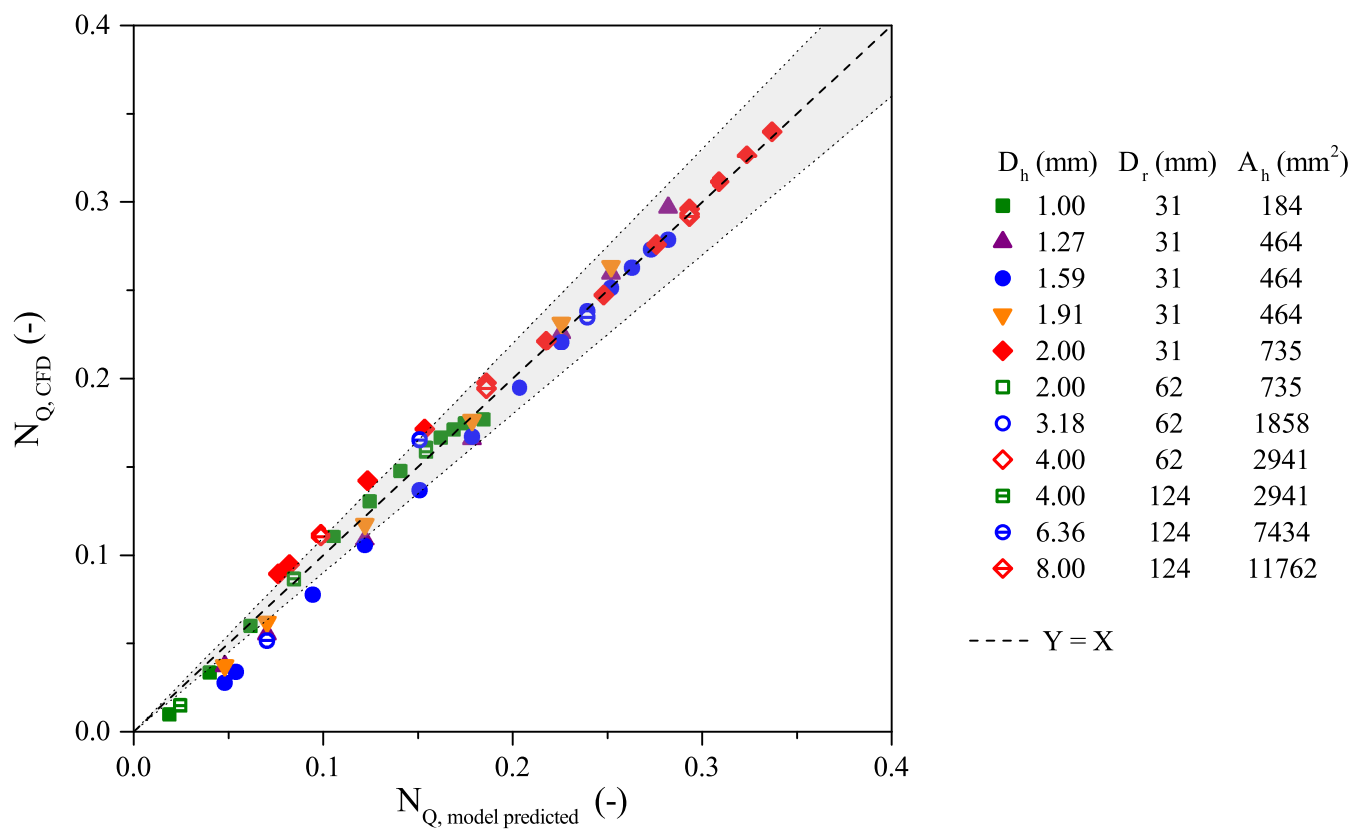

Figure 13: Parity plot showing CFD flow number against predicted one. Dashed line represents $\mathrm{Y}=\mathrm{X}$. Grey area represents $\pm 10 \%$ relative error. $r^{2}$ is 0.99 . Mean absolute error is 0.008 .

\subsection{Effect of rotor-stator gap on power and flow characteristics.}

It is currently unknown how the magnitude of the gap between rotor and the stator affects the power and flow characteristics of rotor-stator mixers, however, this is a variable which commonly changes between different designs of rotor-stator available for companies to purchase. 


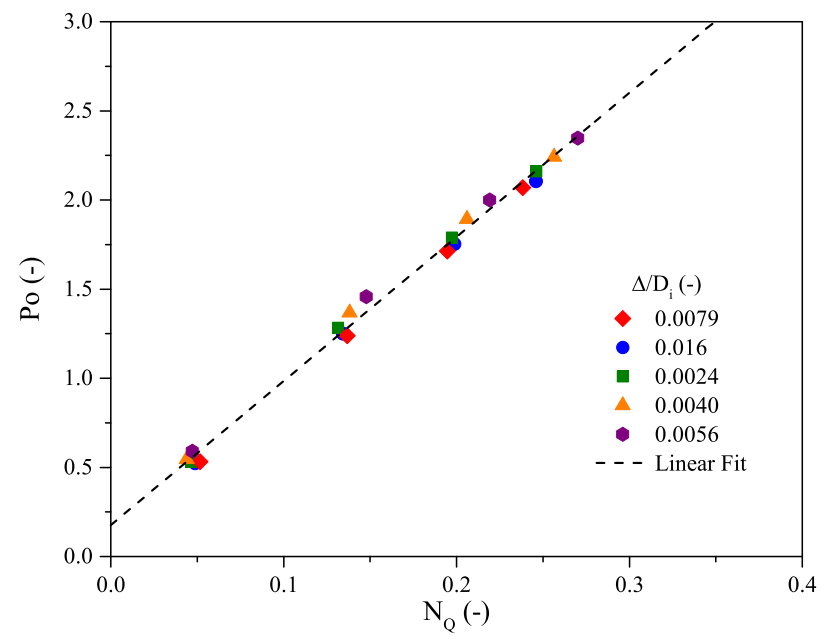

Figure 14: Power number as a function of flow number for various rotor-stator gaps. Dotted line represents a linear fit of the concatenated data. Screen hole size is $1.59 \mathrm{~mm}$ in all cases.

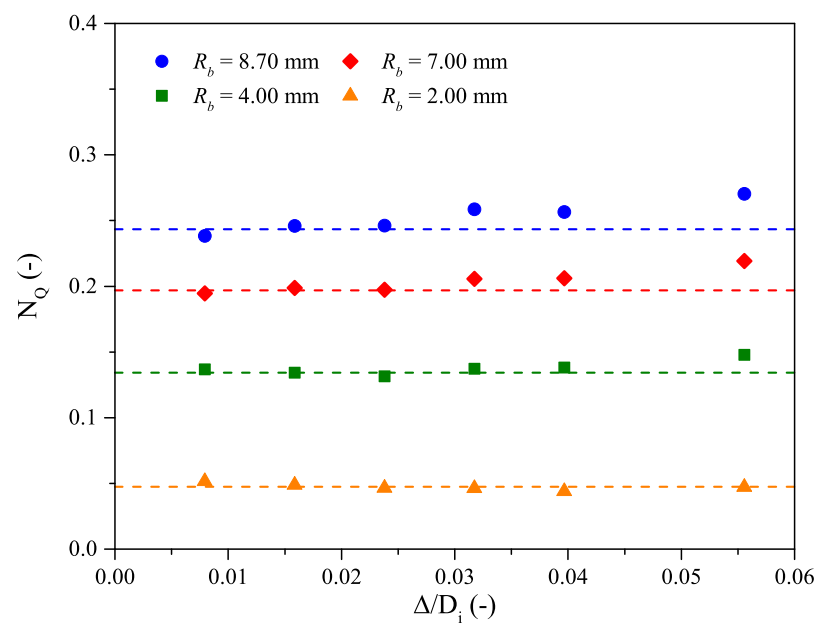

Figure 15: Flow number as a function of rotor-stator gap normalised by inner stator screen diameter for various base sizes. Dotted lines represent the average value of first three data points in each series.

Figure 14 shows the power number as a function of the flow number for rotor-stators with various base diameters and rotor-stator gaps. It can be 
seen that the distance between the rotor and the stator does not appear to change the relationship between the power number and the flow number (ie, it does not affect $k_{1}$ and $\mathrm{Po}_{\mathrm{Z}}$ ). It does, however, appear to affect the flow number and this effect seems to be more prominent for stators with larger base hole areas. This can also be seen in Figure 15 which shows the flow number as a function of the rotor-stator gap normalised by the inner stator screen diameter for various base hole sizes. At large base hole areas, the flow number appears to increase slightly with the magnitude of the rotor-stator gap. The results form Padron (2001) show a decreasing power number as the width of the shear gap is increased, this contractics the results presented here. However, the screen design used in their study was the slotted head design. This could indicate that the effect of varying shear gap width actually changes with the design of the screen. Simulational results from Ghaderzadeh (2018) agree with the results shown in Figures 14 and 15. They found that the power number of an in-line Silverson L4M with a standard emulsor screen increases as the shear gap width is increased. This might be expected, since it is the low pressure behind the rotor blade which is responsible for the recirculation of flow into the holes. At smaller rotor-stator gaps, the low pressure behind the rotor blade is closer to the holes and so fluid will be pulled into the holes at a faster rate. At larger gaps, the low pressure behind the blade is further from the hole and so there is more area available in the holes for the high velocity radial jet, since less fluid is being drawn in, ergo the flow number increases. At small base hole areas, the large majority of the flow enters and leaves through the holes in the screen. Therefore, the gap between the rotor and the stator does not have an effect on the flow number, 
since the amount of fluid entering and leaving through the holes always have to be roughly equal, and since the flow number is normalised by the rotordiameter, the flow number is constant. It can also be seen in Figure 15 that the model shown in Equation (12) is slightly less accurate when predicting flow numbers in stators with small base holes.

The rotor-stator gaps investigated in this study range from the more commonly used gap sizes in industry to gap sizes which are much larger than that typically used in industry. The above conclusions are therefore mainly hypothetical and in reality the gap between the rotor and the stator will not affect power and flow characteristics in most industrial mixers, since the gap is nearly always very small. It can therefore be concluded that when predicting the flow number, the rotor-stator gap does not need to be taken into account.

\section{Conclusions}

This study presents findings from an investigation into how stator geometry affects power and flow characteristics in batch rotor-stator mixers. It was found that in a batch rotor-stator with a standard emulsor head, the flow rate varies through each of the rows of holes in the screen. The non-uniformity in flow between rows increases as the holes size is increased. This is something which has also been observed experimentally for an in-line rotor-stator in a previous study. The empirical constant, $k_{1}$, used in the typical power characterisation of in-line mixers is shown to vary with the ratio of the area of the holes in the screen and the rotor diameter squared. Using this new relationship, we have created a correlation which allows for the prediction of the power number provided that one knows the flow number. This correlation 
is proven to be accurate at predicting power number for various geometries and designs. Data from previous studies, both experimental and simulation based, matched exceptionally well with the model proposed in this study. This correlation is extremely useful to us, since it is far easier to measure the power draw of a batch rotor-stator mixer than it is the flow number. One can measure the power number using experimental torque measurements, and predict the flow number using the new correlation developed in this study. However, it would be even more useful to be able to predict the flow number of the mixer without any experimentation. We therefore have developed another new correlation which enables the prediction of the flow number in batch-rotor stator mixers with the standard emulsor head. This correlation uses a dimensionless number known as the fill ratio to relate the amount of radial flow generated by the mixer to the mixer geometry. This correlation is proven to be accurate at predicting flow numbers for a wide range of stator geometries. It was concluded that the gap between the rotor and the stator had a negligible effect on the flow number and so this variable does not need to be taken into account when trying to predict the flow number. Overall, this study greatly enhances our understanding of the relationship between agitation power, flow, and mixing head geometry in rotor-stator mixers.

\section{References}

Atiemo-obeng, V.A., Calabrese, R.V., Kresta, S.M., 2004. Rotor stator mixing devices, in: Handbook of Industrial Mixing- Science and Practice, pp. 479-505.

Barailler, F., Heniche, M., Tanguy, P.A., 2006. CFD analysis of a rotor-stator mixer with viscous fluids. Chemical Engineering Science 61, 2888-2894. URL: https://doi.org/10.1016/j.ces.2005.10.064, doi:10.1016/j.ces.2005.10.064.

Calabrese, R.V., Chang, T.P.K., Dang, P.T., 1986. Drop breakup in turbulent stirred tank contactors. Part I: Effect of dispersed phase viscosity. AIChE Journal 32, 657-666. 
URL: http://onlinelibrary.wiley.com/doi/10.1002/aic.690320416/abstract, doi:10.1002/aic.690320416.

Carrillo De Hert, S., 2017. Drop size distribution analysis of mechanically agitated liquidliquid dispersions. Ph.d thesis. University of Manchester, UK.

Cooke, M., Rodgers, T.L., Kowalski, A.J., 2011. Power consumption characteristics of an in-line silverson high shear mixer. AIChE Journal 58, 1683-1692. URL: http://doi.wiley.com/10.1002/aic.12703, doi:10.1002/aic.12703.

Davies, J.T., 1985. Drop sizes of emulsions related to turbulent energy dissipation rates. Chemical Engineering Science 40, 839-842. doi:10.1016/0009-2509(85)85036-3.

Davies, J.T., 1987. A physical interpretation of drop sizes in homogenizers and agitated tanks, including the dispersion of viscous oils. Chemical Engineering Science 42, 16711676. doi:10.1016/0009-2509(87)80172-0.

Espinoza, C.J.U., Simmons, M.J.H., Alberini, F., Mihailova, O., Rothman, D., Kowalski, A.J., 2018. Flow studies in an in-line Silverson 150/250 high shear mixer using PIV. Chemical Engineering Research and Design 132, 989-1004. URL: https ://doi.org/10.1016/j.cherd.2018.01.028, doi:10.1016/j.cherd.2018.01.028.

Ghaderzadeh, K., 2018. Crystal wet milling in rotor-stator mixers. Ph.d thesis. University of Maryland, College Park, MD, USA.

Håkansson, A., 2018. Rotor-stator mixers: From batch to continuous mode of operationA review. Processes 6, 32. URL: http://www.mdpi.com/2227-9717/6/4/32, doi:10.3390/pr6040032.

Håkansson, A., Arlov, D., Carlsson, F., Innings, F., 2017. Hydrodynamic difference between inline and batch operation of a rotor-stator mixer head - A CFD approach. The Canadian Journal of Chemical Engineering 95, 806-816. URL: http://doi.wiley.com/10.1002/cjce.22718, doi:10.1002/cjce.22718.

Hall, S., Cooke, M., Pacek, A.W., Kowalski, A.J., Rothman, D., 2011. Scaling up of silverson rotor-stator mixers. The Canadian Journal of Chemical Engineering 89, 1040 1050. URL: http://doi.wiley.com/10.1002/cjce.20556, doi:10.1002/cjce.20556.

Hinze, J., 1955. Fundamentals of the hydrodynamic mechanism of splitting in dispersion processes. AIChe 1, 289-295. doi:10.1002/aic.690010303, arXiv:arXiv:1011.1669v3.

Jasińska, M., Bałdyga, J., Cooke, M., Kowalski, A.J., 2015. Specific features of power characteristics of in-line rotorstator mixers. Chemical Engineering and Processing: Process Intensification 91, 43-56. URL: http://linkinghub.elsevier.com/retrieve/pii/S0255270115000720, doi:10.1016/j.cep.2015.03.015. 
John, T.P., Fonte, C.P., Kowalski,

A., Rodgers, T.L., 2019.

A comparison of power and flow characteristics between batch and in-line rotor-stator mixers. Chemical Engineering Science URL: http://www.sciencedirect.com/science/article/pii/S0009250919302301, doi:https://doi.org/10.1016/j.ces.2019.03.015.

Kowalski, A.J., 2009. An expression for the power consumption of in-line rotor-stator devices. Chemical Engineering and Processing: Process Intensification 48, 581585. URL: http://linkinghub.elsevier.com/retrieve/pii/S0255270108000998, doi:10.1016/j.cep.2008.04.002.

Kowalski, A.J., Cooke, M., Hall, S., 2011. Expression for turbulent power draw of an in-line Silverson high shear mixer. Chemical Engineering Science 66, 241-249. URL: http://dx.doi.org/10.1016/j.ces.2010.10.010, doi:10.1016/j.ces.2010.10.010.

Malavasi, S., Messa, G., Fratino, U., Pagano, A., 2012. On the pressure losses through perforated plates. Flow Measurement and Instrumentation 28, 57-66. URL: http://dx.doi.org/10.1016/j.flowmeasinst.2012.07.006, doi:10.1016/j.flowmeasinst.2012.07.006.

Minnick, B.A., Kim, J.W., Ko, D.I., Calabrese, R.V., 2018. Flow and power characteristics of an axial discharge rotor-stator mixer. Chemical Engineering Research and Design 136, 477-490. URL: https://doi.org/10.1016/j.cherd.2018.05.015, doi:10.1016/j.cherd.2018.05.015.

Mortensen, H.H., Arlov, D., Innings, F., Håkansson, A., 2018. A validation of commonly used CFD methods applied to rotor stator mixers using PIV measurements of fluid velocity and turbulence. Chemical Engineering Science 177, 340353. URL: http://linkinghub.elsevier.com/retrieve/pii/S0009250917307169, doi:10.1016/j.ces.2017.11.037.

Mortensen, H.H., Calabrese, R.V., Innings, F., Rosendahl, L., 2011. Characteristics of batch rotor-stator mixer performance elucidated by shaft torque and angle resolved PIV measurements. Canadian Journal of Chemical Engineering 89, 1076-1095. doi:10.1002/cjce.20587.

Mortensen, H.H., Innings, F., Håkansson, A., 2017. The effect of stator design on flowrate and velocity fields in a rotor-stator mixerAn experimental investigation. Chemical Engineering Research and Design 121, 245-254. URL: http://dx.doi.org/10.1016/j.cherd.2017.03.016, doi:10.1016/j.cherd.2017.03.016.

Özcan-Taşkın, G., Kubicki, D., Padron, G., 2011. Power and flow characteristics of three rotor-stator heads. The Canadian Journal of Chemical Engineering 89, 1005-1017. URL: http://doi.wiley.com/10.1002/cjce.20553, doi:10.1002/cjce.20553.

Padron, G., 2001. Measurement and comparison of power draw in batch rotor-stator mixers. M.sc thesis. University of Maryland, College Park, MD, USA. 
Rielly, C.D., Gimbun, J., 2009. Computational Fluid Mixing. Wiley Blackwell, Chichester. URL: https://dspace.lboro.ac.uk/2134/5446, doi:10.1002/9781444312928.ch8.

Rodgers, T.L., Cooke, M., 2012. Rotor-stator devices: The role of shear and the stator. Chemical Engineering Research and Design 90, 323-327. doi:10.1016/j.cherd.2011.07.018.

Utomo, A., Baker, M., Pacek, A., 2009. The effect of stator geometry on the flow pattern and energy dissipation rate in a rotorstator mixer. Chemical Engineering Research and Design 87, 533-542. URL: http://linkinghub.elsevier.com/retrieve/pii/S0263876208003511, doi:10.1016/j.cherd.2008.12.011.

Utomo, A.T., Baker, M., Pacek, A.W., 2008. Flow pattern, periodicity and energy dissipation in a batch rotor-stator mixer. Chemical Engineering Research and Design 86, 1397-1409. URL: http://dx.doi.org/10.1016/j.cherd.2008.07.012, doi:10.1016/j.cherd.2008.07.012. 